\title{
Documento
}

\section{Uma tradução de On Picturesque Beauty, de William Gilpin}

\author{
A translation of William Gilpin's On the Picturesque Beauty
}

DOI: $10.20396 /$ rhac.v2i1.15335

GUSTAVO LOPES DE SOUZA

Professor no Departamento de Artes Visuais da Universidade de Brasília

(D) 0000-0001-7920-9357

\section{Resumo}

O presente texto consiste de uma tradução ao português do ensaio On Picturesque Beauty (Sobre a Beleza Pitoresca), publicado originalmente em 1792. Seu autor, o clérigo anglicano William Gilpin (1724-1804), discute nele as características que, quando presentes em objetos, os tornam pitorescos, ou seja, especialmente adequados à representação pictórica. Gilpin defende que a aspereza é a característica pitoresca por excelência. Diferenciando a beleza natural dos objetos lisos da beleza pitoresca de objetos tais como ruínas, pelagens grosseiras e rostos enrugados, o autor associa a esta beleza, também, as pinceladas bruscas e o movimento vigoroso, evidenciando, através de exemplos, as afinidades entre seus valores estéticos e a arte barroca, e contribuindo para a sustentação teórico-crítica da arte romântica.

Palavras-chave: William Gilpin. Barroco. Pitoresco. Romantismo. Ruínas.

\begin{abstract}
This text consists of a translation into Portuguese of the essay On Picturesque Beauty, first published in 1792. Its author, Anglican cleric William Gilpin (1724-1804), discusses therein those qualities that, when present in objects, render them picturesque, that is, particularly apt to be represented in painting. Gilpin argues that roughness is the chief picturesque quality. Distinguishing between the real beauty of smooth objects and the picturesque beauty of objects such as ruins, rough animal's coats and wrinkled faces, Gilpin also links this kind of beauty to vigorous movement and rough brush stokes, bespeaking thereby of the affinities between his aesthetic values and Baroque art, and contributing, moreover, to the theoretical and critical underpinning of Romantic art.
\end{abstract}

Keywords: William Gilpin. Baroque. Picturesque. Romanticism. Ruins.

\section{Nota Introdutória}


Homem de múltiplos talentos, o clérigo anglicano e educador iluminista William Gilpin (17241804) dedicou-se, também, à estética e à teoria da arte, contribuindo para forjar o conceito sobre o qual repousa a maior parte de sua fama duradoura: o pitoresco.

Seu primeiro escrito sobre arte, Dialogue upon the gardens of the Right Honourable the Lord Viscount Cobham, at Stow in Buckinghamshire (1748) discorre, sob forma de um diálogo fictício, sobre as qualidades artísticas e paisagísticas dos suntuosos jardins indicados no título. O convívio com o jardim setecentista inglês, do qual os de Stowe são exemplos modelares, ajuda a explicar várias das ideias de Gilpin sobre arte e beleza. Em contraste com o jardim barroco francês, caracterizado pela simetria e pela vegetação elaboradamente podada, buscava-se no inglês uma artificialidade menos ostensiva, na qual, graças à irregularidade do traçado, a natureza e a ação humana parecessem se integrar de modo mais orgânico. Características de tais jardins - que devem ter, igualmente, contribuído para a formação das ideias de Gilpin - eram as follies, construções puramente decorativas cujo aspecto sugeria um outro e fictício uso, como a imitação de um castelo gótico em ruínas.

Embora já se esboce, no Diálogo, o essencial do pensamento estético de Gilpin, é em trabalhos posteriores, como An Essay on Prints (1768) e On Picturesque Beauty (1792), que ele o expõe de modo mais sistemático. Entre suas ideias principais está a distinção entre a beleza intrínseca, que agrada quando presente nos objetos em si mesmos, e a beleza pitoresca, que se evidencia quando esses objetos são representados na pintura. Nem tudo, sustenta Gilpin, se presta a uma bela representação com o mesmo grau de sucesso: objetos irregulares, como ruínas (tema frequente de suas aquarelas), resultariam, quando pintados, mais atraentes que objetos regulares, como um palácio neoclássico. De modo similar, a lisura e a estabilidade parecem para Gilpin inadequadas à pintura, preferindo ele a rudeza, como a da pelagem grosseira de um cavalo de carga, e o movimento, como o de músculos agitados por um intenso esforço físico. A temas e objetos desse tipo Gilpin chama pitorescos, ou seja, especialmente adequados à representação pictórica.

Nada poderia ser mais distante dos valores estéticos que, décadas antes, eram defendidos na Europa continental pelo influente pensador alemão Johann Winckelmann (1717-1768). Enquanto Gilpin laudava o movimento vigoroso, Winckelmann exigia da arte uma grandeza serena; se o inglês, ao discutir a pintura, pensava sobretudo em termos de pinceladas e manchas, de luzes e sombras, Winckelmann a concebia, em primeiro lugar, em termos de clareza e nobreza de contorno. Em resumo, para usarmos os termos consagrados por Heinrich Wölfflin (1864-1945), a estética de Gilpin é pictórica, ao passo que a de Winckelmann é linear. 
Com efeito, o conceito de pictórico, tal qual Wölfflin o concebe, coincide em grande medida como o pitoresco de Gilpin, e, não por acaso, ambos os autores recorrem, ao ilustrá-los, a obras barrocas. Sem ser, como os ensaios do britânico, prescritiva ou laudatória, a obra historiográfica de Wölfflin se insere no contexto da revalorização estética do período barroco, defendendo que a este se julgasse de acordo com seus próprios objetivos e valores, diferentes dos renascentistas, mas não inferiores a estes. A obra de Gilpin, de intenção e escopo diversos, antecipa esse revisionismo.

Mas não é só com o passado que Gilpin dialoga. Ele o utiliza, como o fez Wickelmann, como alicerce de sua crítica ao presente e sua visão do futuro. Assim como Winckelmann em relação ao Neoclassicismo, Gilpin assistiu à gênese do período estilístico cujos fundamentos teóricos ajudou a traçar: a pincelada vigorosa e não-dissimulada, o gosto pelas ruínas e pela rudeza - tudo isso é barroco, mas é também romântico. E, difícil como seja mensurar, em casos assim, relações de causa e efeito, os rumos que tomou a arte romântica europeia corresponderam, em boa parte, àquilo que Gilpin prescrevia. A obra extremamente pitoresca de um pintor como William Turner (1775-1851), cujos primeiros trabalhos são contemporâneos aos anos finais de Gilpin, teria decerto agradado a este, como o teriam as ruínas artificiais neogóticas que, depois de sua morte, continuariam a se multiplicar pela Europa, repercutindo depois em outras partes do mundo. ${ }^{1}$ Do outro lado do Atlântico, para além das ruínas e do Romantismo, um rumor distante de seu pensamento ecoaria na land art de Robert Smithson².

\section{Sobre a Beleza Pitoresca ${ }^{3}$}

Debates sobre a beleza poderiam, talvez, envolver menos confusão se estabelecêssemos uma distinção, que certamente existe, entre objetos belos e objetos pitorescos-entre aqueles que, em seu estado natural, agradam ao olho, e aqueles que agradam devido àquela qualidade evidenciada na representação pictórica.

Os critérios de beleza variam de acordo com o objeto e com o olho do observador. As formas artificiais que, normalmente, nos parecem as mais belas são aquelas com as quais somos mais familiares.

\footnotetext{
${ }^{1}$ Veja-se, por exemplo, as ruínas artificiais no Jardim Botânico Rodrigues Alves e na Praça Batista Campos, em Belém do Pará. (Nota do Tradutor)

${ }^{2}$ Sobre a repercussão do pitoresco gilpiniano na obra de Smithson, ver: MARTIN, Thimothy D. Robert Smithson and the AngloAmerican Picturesque. In: PEABODY, Rebecca (Org.) Anglo-American Exchange in Post-war Sculpture. Los Angeles: Getty, 2011 p. 164-174. Disponível em: https://www.getty.edu/museum/symposia/pdf_stark/stark_tmartin.pdf. Acesso em: 12 mai. 2021. (N. do T.)

${ }^{3}$ Utilizou-se para esta tradução o texto tal como encontrado em: GILPIN, William. Three Essays: on picturesque beauty; on picturesque travel; and on sketching landscape: to which is added a poem, on landscape painting. Londres: R. Blamire, 1794 Disponível em: https://archive.org/details/threeessaysonpicoogilp_o. Acesso em: 12 mai. 2021. (N. do T.)
} 
O pedreiro, portanto, verá beleza em uma parede cujas pedras se ajustem bem, o que escapa ao arquiteto, que julga a construção sob um critério diferente. Do mesmo modo, o pintor, ao julgar seu objeto pelas regras de sua arte, enxerga-o sob luz diversa daquela do homem de gosto comum, que se pergunta, simplesmente, se esse objeto é belo.

Assim, uma vez que a diferença entre o belo e o pitoresc $0^{4}$ parece de fato existir, e depende necessariamente de uma constituição específica do objeto, talvez valha a pena examinar em que exatamente esta consiste. Não investigamos aqui as causas gerais da beleza, seja na natureza, seja na representação. Isso levaria a uma erudita e agradável discussão, na qual não desejamos envolver-nos. Nossa questão é, simplesmente, que qualidade, quando presente em objetos, caracteriza-os como especialmente pitorescos?

Ao estudarmos o objeto em si mesmo, descobriremos que uma das fontes da beleza deriva daquele tipo de elegância ao qual chamamos lisura, ou lustro; pois os termos são quase sinônimos. Quanto mais polido o mármore, mais esfregada a prata e mais brilhante o mogno, mais belos os consideramos: como se olho se deleitasse em deslizar suavemente sobre uma superfície.

No caso de objetos maiores a mesma ideia prevalece. Ao avaliarmos uma grande construção, desejamos ver esmero na execução aliado a elegância na arquitetura. E, se observamos um jardim ornamentado ${ }^{5}$, toda parte acidentada e rústica nos desagrada.

O Sr. Burke, ao enumerar as propriedades da beleza, considera a lisura uma das mais essenciais. "Uma parte considerável do efeito da beleza, diz ele, se deve a essa qualidade: com efeito, a mais considerável: pois tome qualquer belo objeto, e conferira-Ihe uma superfície irregular e áspera, e, não importa quão bem constituído possa ser noutros aspectos, ele não mais o agrada. Ao passo que, não importa quão deficientes seus outros aspectos possam ser, não lhe faltando lisura ele se torna mais aprazível que quase todos os que não a têm." ${ }^{6}$ Sobre quão certo o Sr. Burke está ao considerar a lisura a fonte principal da beleza, eu tenho minhas dúvidas. ${ }^{7}$ Importante ela certamente é.

\footnotetext{
4 "Picturesque" no original. A palavra é utilizada por Gilpin em dois sentidos distintos: o de "pitoresco" (ou seja, especialmente adequado à representação pictórica) e o de "pictórico" (ou seja, representado por meio da pintura). Optou-se, de acordo com o contexto, por traduzir um mesmo vocábulo às vezes de um modo, às vezes de outro, evitando-se forçar uma identidade que não existe em língua portuguesa. (N. do T.)

5 "Improved pleasure-ground" no original, sem equivalente preciso em português. O pleasure ground consiste da parte mais ornamentada de um jardim inglês, normalmente cercada e localizada nas adjacências de uma residência. Cf.: PÜCKLERMUSKAU, 1998 apud NUCCI, João Carlos; SANTOS, Douglas Comes dos. Paisagens geográficas: um tributo a Felisberto Cavalheiro. Campo Mourão: FECILCAM, 2009. p. 36. (N. do T.)

${ }^{6}$ Sobre o sublime e o belo, p. 213. (Nota do Autor)

7 O Sr. Burke provavelmente não está muito correto quando afirma, mais adiante, sobre a conexão entre a beleza e os diminutivos. A beleza instiga o amor; e um objeto amado é geralmente chamado por diminutivos. Mas disso não se segue que todos os objetos assim chamados - embora possam ser belos, uma vez que são amados - devam ser belos necessariamente. Com frequência os amamos por suas qualidades morais, seu afeto, sua gentileza ou sua docilidade. A beleza, sem dúvida, desperta o amor, mas também instiga admiração e respeito. Essa combinação compõe o sentimento que prevalece quando
} 
Eis então, supomos, o estado da questão no que toca aos objetos belos em geral. No entanto, no que toca à representação pictórica, descobriremos talvez que, estranho como possa parecer, o oposto é igualmente verdadeiro; e que os conceitos de lisura e lustro, em vez de serem pitorescos, na verdade desqualificam de toda pretensão à beleza pitoresca o objeto no qual residem. - Mais ainda, não temos escrúpulos em afirmar que a aspereza constitui o ponto mais essencial de diferença entre os objetos belos e os objetos pitorescos, na medida em que parece ser ela a qualidade que torna estes últimos aprazíveis na pintura. - Utilizo aqui o termo geral aspereza; mas propriamente falando a aspereza relaciona-se apenas à superfície dos corpos. Ao falarmos de seu contorno, usamos o termo irregularidade. Ambos os conceitos, contudo, participam igualmente do pitoresco; e ambos se observam nas menores coisas da natureza, bem como nas maiores - tanto no contorno e na casca de uma árvore quanto no áspero cume e nos escarpados flancos de uma montanha.

Examinemos então nossa teoria por meio de um apelo à experiência; e vejamos até que ponto essas qualidades participam do conceito de beleza pitoresca; e até que ponto elas constituem aquela diferença entre objetos que constitui o escopo de nossa investigação.

Uma construção no estilo paladiano ${ }^{8}$ pode ser elegante no mais alto grau. A proporção das partes, a adequação dos ornamentos e a simetria do conjunto podem ser sumamente agradáveis. Mas se a introduzirmos em uma pintura, ela se torna imediatamente um objeto formal, e deixa de agradar. Para Ihe conferirmos beleza pitoresca, devemos usar o martelo em vez do cinzel: devemos demolir uma metade, danificar a outra e empilhar em volta as partes mutiladas. Em resumo, devemos fazer de um prédio liso uma ruína áspera. Pintor algum, ao escolher entre os dois, hesitaria um instante.

Novamente, por que um jardim elegante não causa impressão quando pintado? A forma é agradável; a combinação dos objetos, harmoniosa; e o alargamento dos caminhos ondula numa perfeita linha de beleza. ${ }^{9}$ Tudo isso é verdade; mas a lisura do conjunto, embora correta, tal como se mostra na realidade, torna-se desagradável na pintura. Transforme o gramado em um terreno irregular: plante carvalhos rugosos em vez de arbustos floridos: desfaça as bordas dos caminhos: dê-lhes a rudeza de uma estrada; sulque-os com marcas de rodas; e espalhe em volta algumas pedras e algum mato: numa palavra,

\footnotetext{
observamos o Apolo de Belvedere e a Níobe. Nenhum homem de bom senso chamaria estas estátuas por diminutivos. Existe, então uma beleza com a qual os diminutivos não têm relação; mas que, ao contrário, os exclui: e, ao descrever figuras imbuídas desta espécie de beleza, procuramos por termos que Ihes associem mais à nossa admiração que ao nosso amor. (N. do A.)

${ }^{8}$ Estilo arquitetônico de tendências classicistas, baseado nas edificações e nos escritos do arquiteto veneziano Andrea Palladio (1508-1580). (N. do T.)

${ }^{9}$ Gilpin refere-se aqui à linha serpentina - em forma de "S" -, considerada o tipo mais belo de linha pelo pintor, cartunista e teórico inglês William Hogarth (1697-1764). Ver, a esse respeito: HOGARTH, William. The analysis of beauty. Pittsfield: The Silver Lotus, 1909. Disponível em: https://archive.org/stream/analysisbeautyoohogagoog\#page/n11/mode/2up. Acesso em: 12 mai. 2021. (N. do T.)
} 
em vez de torná-la liso, torne-o áspero; e você o terá, também, tornado pitoresco. Todos os outros ingredientes da beleza ali já se encontram.

Você posa para um retrato. O mestre, a seu pedido, pinta sua cabeça cuidadosamente penteada e empoada pelas mãos do barbeiro. ${ }^{10}$ Talvez lhe dê, assim, uma semelhança mais notável, na medida em que se parece mais com o modelo real. Mas o retrato se torna, por isso, mais agradável? Temo que não. Deixe-o ao encargo de Reynolds"1 e este o tornará pitoresco: jogará seu cabelo desalinhado sobre seus ombros. Virgílio faria o mesmo. Era seu costume em todos os retratos. Em sua descrição de Ascânio, temos os fusos crines ${ }^{12}$; e em seu retrato de Vênus, sumamente detalhado em cada aspecto, o artista oferece seus cabelos

...diffundere ventis ${ }^{1314}$

Fazem o mesmo aqueles que, dentre os poetas modernos, pensaram de algum modo a beleza natural. Tomo Milton como exemplo deles todos. Em seu retrato de Eva, ele nos diz que

... até sua fina cintura

Suas douradas e despojadas tranças pendiam

Desalinhadas, e em selvagens cachos ondulavam

Aquela adorável e sorridente face da juventude, com toda a doçura de seus encantos, que atraente é na realidade! Que bela é na representação! É um daqueles temas que, como tantos outros, agradam tanto na natureza quanto numa tela.

\footnotetext{
${ }^{10}$ Entre as classes médias e altas europeias do século XVIII, considerava-se elegante embranquecer com pó o cabelo ou a peruca, indumentária então em moda. (N. do T.)

${ }^{11}$ Famoso, também, por suas paisagens, Joshua Reynolds (1723-1792) foi um dos mais célebres pintores de retratos da Inglaterra do seu tempo. (N. do T.)

12 "cabelos revoltos". (N. do T.)

13 "[para] o vento desarrumar". (N. do T.)

${ }^{14}$ A rudeza que Virgílio confere aos cabelos de Vênus é, podemos supor, de um tipo diferente da rudeza esquálida que ele atribui a Caronte:
}

\author{
Portitor has horrendus aquas, et flumina fervat \\ Terribili squalore Charon, cui plurima mento \\ Canities inculta jacet. ..."
}

[Virgílio, Eneida, Livro VI, 298-300. Em tradução de Odorico Mendes, "Fero esquálido arrais guarda essas águas, / Caronte hediondo, cuja barba espessa/ Branqueia inculta ..."] (N. do T.)

\footnotetext{
A rudeza de Caronte é, à sua maneira, igualmente pitoresca, mas a rudeza a que nos referíamos, e que só se aplica a figuras elegantes, é daquele tipo que se opõe apenas ao cabelo cuidadosamente arrumado. Ao descrever Vênus, Virgílio provavelmente considerava o cabelo, quando agitado pelo vento, tão belo quanto pitoresco, devido à sua forma ondulante e aos seus tons variados, e devido à vitalidade que ele assume quando em movimento; embora o que talvez mais o interessasse, nessa ocasião, fosse o fato de que tal movimento compunha o caráter que Vênus, naquele momento, assumia. (N. do A.)
} 
Mas se o que se quer ver é a face humana em seu grau mais elevado de beleza pitoresca, contemplese a cabeça de um patriarca. O que lhe confere aquela dignidade de caráter? Aquela força de expressão: aquelas linhas de sabedoria e experiência; aquela expressividade vigorosa, tão acima do frescor rosado, ou mesmo do encantador sorriso da juventude? O que, senão a testa marcada de rugas? A proeminente maçã do rosto, banhada de luz? Os músculos das faces, fortemente marcados, desaparecendo na barba hirsuta? E, sobretudo, as sobrancelhas austeras, projetando-se sobre os olhos - detalhe que, acima de todos, marcou Homero ao elaborar seu Júpiter ${ }^{15}$, e que ele provavelmente vira representado em uma estátua? O que, numa palavra, senão os ásperos sinais da idade?

Como objeto de beleza mista, que participa tanto do belo quanto do pitoresco, admiramos igualmente o corpo humano. Tão infinitamente variadas são as linhas e a superfície de uma bela figura humana; tão esplendidamente suaves são as luzes e sombras que recebe em certas partes, e contudo, em outras, tão curvas e bruscas; tão justas são suas proporções; e tão aptos são seus membros a receber todas as belezas da graciosidade e do contraste, que mesmo a face, na qual residem os encantos da inteligência e da sensibilidade, quase desaparece na comparação. Mas embora a figura humana seja bela num estado de repouso, quanto mais sua superfície lisa se ondular, por assim dizer, mais pitoresca ela será. Quando é agitada pela emoção, e seus músculos se intumescem pelo esforço intenso, ela aparece então sob a luz mais favorável - Mas ao falarmos do efeito do esforço sobre os músculos, nos referimos apenas aos esforços naturais, não a uma artificial demonstração anatômica, na qual os músculos, embora posicionados corretamente, parecem ainda assim sobrecarregados.

É verdade que, entre as representações que normalmente encontramos, as da figura humana num estado quiescente nos agradam mais que as agitadas: mas isso se deve apenas ao fato de que raramente a vemos representada em movimento vigoroso com naturalidade. O conhecimento da anatomia é escasso mesmo entre os melhores mestres. Um estufará os músculos violentamente para um

\footnotetext{
${ }^{15}$ É muito mais provável que o poeta tenha copiado as formas do escultor, que, supõe-se, as compreendia melhor, por tê-las estudado mais profundamente, do que o escultor as tenha copiado do poeta. Os artistas, contudo, tiraram vantagem da fama universal de Homero para assegurar a aprovação de suas obras, na medida em que as apresentavam como imagens refletidas das concepções do poeta. Desse modo, Fídias assegurou seus conterrâneos que ele emprestara seu Júpiter à descrição daquele deus no quinto livro de Homero. O fato é que nenhuma das características presentes nesta imagem, exceto o cenho, pode ser representada pela escultura. Mas ele sabia que vantagem tais concepções, tanto quanto sua arte as podia expressar, receberiam da associação, na mente do observador, com as concepções poéticas, bem como da justa parcialidade dos homens por tal poeta.

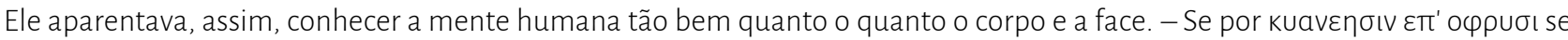
compreende, conforme acreditamos, uma sobrancelha proeminente, que lança uma grande e profunda sombra sobre o olho. Carke [Samuel Clarke (1675-1729), teólogo e filósofo inglês, traduziu para o latim a llíada e a Odisseia. (N. do T.)] o traduziu mal por nigris superciliis, que a maioria das pessoas compreenderia como sobrancelhas negras. Tampouco Pope [Alexander Pope (1688-1744), um dos maiores poetas britânicos, traduziu para o inglês a llíada e parte da Odisseia (N. do T.).], embora parecesse entender de pintura, o traduziu melhor por "sobrancelhas sombrias".) Mas se Fídias nada teve que o recomendasse, exceto seu uso desse único detalhe de Homero que se adequava à sua arte, não ouviríamos falar de investigações sobre onde ele teria obtido suas ideias; nem do agradecimento que o empréstimo lhe permitiu fazer a Homero. (N. do A.)
} 
movimento discreto: outro mal os distenderá ao representar um grande esforço. O olho logo aprende a enxergar um defeito, embora não o possa remediar. Mas quando a anatomia é perfeitamente correta, o corpo humano será sempre mais pitoresco em ação que em repouso. Os antigos mestres da escultura parecem ter se dado conta da grande dificuldade em representar um forte movimento muscular: pois é certamente muito mais difícil modelar a partir de uma figura em ação vigorosa e fugaz, que se deve, por assim dizer, alvejar em voo, que a partir de uma figura sentada ou de pé, que o artista pode copiar com calma. Dentre a variedade de estátuas produzidas por suas mãos, restam-nos apenas três ou quatro em movimento vigoroso ${ }^{16}$. E, no entanto, quando observarmos a boa execução de um efeito desse tipo, nossa admiração cresce consideravelmente. Quem não admira o Laocoonte mais que ao Antínoo?

A vida animal, bem como a humana, é, em geral, bela tanto na realidade quanto na tela. Admiramos o cavalo em si mesmo; a elegância de sua forma; a dignidade de seu trote; o vigor de todos os seus movimentos; e o brilho de seu pelo. Admiramo-lo também na representação. Mas como objeto de beleza pitoresca, admiramos mais o exaurido cavalo de tração, a vaca, o bode ou o burro, cujas linhas mais rudes e pelagens mais grosseiras exibem melhor os poderes do pincel. Podemos confirmá-lo nas pinturas de Berchem ${ }^{17}$ : observamo-lo na hábil pincelada de Rosa de Tivoli ${ }^{18}$. O leão com sua juba rude, o javali hirsuto e a plumagem eriçada da águia' ${ }^{19}$ são temas desse tipo. Animais de pelagem lisa não produzem um efeito tão pitoresco.

\footnotetext{
${ }^{16}$ Embora, provavelmente, existam apenas duas ou três estátuas antigas em movimento vigoroso - o Laocoonte, o gladiador em luta e os boxeadores - ainda assim há várias outras que apresentam movimento. - o Apolo Belvedere, o Torso de Michelangelo, Arria e Paetus, a Pietas Militaris - às vezes chamada de Ajax, do qual fazia parte o Pasquino de Roma, e do qual há uma cópia mais completa, embora mais mutilada, em Florença -, o Alexandre e Bucéfalo e talvez outras cuja lembrança me escapa. Penso, contudo, que sua escassez, ainda que se produzisse um catálogo um catálogo mais longo, mostra que os escultores antigos consideravam a representação do movimento vigoroso uma façanha. Os modernos foram menos ousados em tentá-la. Mas acredito que, via de regra, os apreciadores dão preferência àquelas estátuas nas quais os grandes mestres exibiram com sucesso o movimento intenso. (N. do A.)

${ }^{17}$ Nicolaes Pieterszoon Berchem (1620-1683), pintor holandês conhecido sobretudo por suas paisagens campestres e cenas de gênero. (N. do T.)

${ }^{18}$ Philipp Peter Roos (1655-1706), pintor alemão, radicado, entre c. 1684 e 1691, na cidade italiana de Tivoli, e conhecido sobretudo por suas paisagens com animais. (N. do T.)

${ }^{19}$ A ideia da plumagem eriçada da águia provém da celebrada águia de Píndaro, em sua Primeira Ode Pítica; a imagem, cantada desde então por vários outros poetas, é tão poética quanto pitoresca; é considerada um caso exemplar do poder da música. Em sua Ode ao progresso da poesia, Gray a descreve do seguinte modo:
}

Tua mágica serena o emplumado rei

De eriçadas penas e asas fatigadas

Pousado na mão imperial de Júpiter:

Sossegados nas negras nuvens do sono

O terror do seu bico e o raio em seu olho.

Ao retratá-las em seu hino às Náiades, Akenside as pinta com um pouco mais de rigidez:

Com asas em repouso,

Enquanto o solene concerto ressoa ao redor, 
Mas quando o pintor prefere o cavalo de tração, a vaca ou o burro a outros temas mais belos em si mesmos, ele certamente não torna sua obra desejável àqueles cujo amor pela beleza os faz buscar ansiosamente os meios de se capturar suas formas fugidias.

Sugestões desse tipo são ingratas. A arte da pintura permite tudo o que se possa desejar. Se é um belo tema o que você quer ver pintado - seu cavalo, por exemplo, a sair do estábulo em toda a sua festejada beleza - a arte da pintura está pronta a acolhê-lo. Você possui então a bela forma que admirava na realidade transferida para a tela com exatidão. Fique, pois, satisfeito. A arte da pintura lhe deu o que queria. Se o pintor crê que os poderes de sua arte seriam mais claramente exibidos ao pintar seu cavalo de tração, isso em nada prejudica a beleza de seu cavalo árabe.

Mas não deprecia a sua arte o pintor que pretere uma figura bela por outra menos bela tãosomente porque, ao fazê-lo, os poderes de sua arte seriam mais claramente exibidos - porque suas linhas rústicas favorecem uma maior facilidade na execução? Seria a pincelada hábil a realização suprema da pintura? Descobrirá ele em temas pitorescos nada mais que aquelas qualidades adequadas à representação vivaz?

Eu não o defenderia se ele assim agisse. Ainda assim, a execução livre é uma parte tão fascinante da pintura, que não devemos estranhar que o artista a valorize em alto grau. Contudo, a preferência do artista por linhas rústicas não se deve apenas à dificuldade de se dominar uma linha elegante. Em parte, esse pode realmente ser o caso; pois se uma linha elegante não for traçada com a maior precisão, ela se torna a mais insípida das linhas: ao passo que, na representação de um objeto rústico, um erro de traçado é mais dificilmente percebido. A questão, no entanto, não consiste apenas disso. Uma pincelada habilidosa e livre é agradável em si mesma ${ }^{20}$. Em figuras elegantes é preciso, de fato, que o contorno seja elegante - ou pelo menos fiel à natureza: mas mesmo superfícies desse tipo podem ser pintadas

Pousada no cetro de seu senhor

Dorme a águia severa; conquistada pelas notas numeradas;

E saciada do tom suavizante;

Soberana entre os pássaros. ..

A versão de West, sobretudo nas duas últimas linhas, é muito boa.

A feroz rainha dos pássaros relaxa sua ira vingativa,

Pousada no cetro do rei Olímpico,

sente o enlevante poder da harmonia

E deixa, indolente, cair suas asas lânguidas:

Enquanto o sono gentil sela seus olhos,

E sobre seus membros pesados, em desalinho,

Dançam ao vento suas penas eriçadas. (N. do A.)

20 Podemos chamar livre a uma pincelada quando não há nela aparência de cuidado. Ela é habilidosa quando de uma parte se depreende o todo, o qual ela deve necessariamente sugerir. Eis o laconismo do gênio. Mas, às vezes, ela pode ser livre e sugerir apenas quão facilmente se pode executar uma linha sem significado. Tal linha não é habilidosa, mas impudente. (N. do A.) 
livremente; e, ao seu redor, deve-se introduzir objetos mais grosseiros, ou o contraste ficará a desejar. Tais objetos são, via de regra, admirados em paisagens; o que dá livre rédea à execução. Pouca beleza resulta de um pincel tímido ou hesitante. A execução, assim, agrada somente quando a mão firme e segura pinta livremente as partes características de cada objeto.

Com efeito, tanto na literatura quanto na pintura, se você desvia do assunto a atenção do público, e a atrai para a maneira de executá-lo, sua artificialidade não agrada. ${ }^{21}$ Ao mesmo tempo, se certo cuidado e certo esforço não forem despendidos na execução, sua rusticidade desagrada igualmente. Uma verdade é uma verdade, seja ela expressa pela linguagem de um filósofo ou pela de um camponês: e o intelecto a recebe como tal. Mas o artista, que trabalha com linhas, superfícies e cores, as quais dirigem-se diretamente ao olho, concebe a própria verdade, em si mesma, como integrada ao seu modo de representála. $\mathrm{O}$ anjo de $\mathrm{Guido}^{22}$ e anjo em uma placa na rua são seres muito diferentes; mas toda a diferença consiste em uma habilidosa execução das linhas, das superfícies e das cores.

Mas não é somente pela sua execução que o artista valoriza um objeto áspero. Ele encontra neste vários outros aspectos que se adequam à sua arte. Em primeiro lugar, sua composição o requer. Se o pintor de temas históricos cobrisse de vestes sem dobras todas as suas figuras, seus grupos e combinações tornar-se-iam bastante esquisitos. E na pintura de paisagem objetos lisos não produzem qualquer composição. Numa paisagem montanhosa, que combinação pode haver quando uma encosta suave se ergue de um lado, uma encosta suave a interrompe de outro, uma planície suave queda-se, talvez, no meio e suaves montanhas são contempladas ao fundo? A própria ideia é repelente. A composição pitoresca consiste em unir num todo a variedade das partes; e esta só se pode obter de objetos ásperos. Se as suaves montanhas e planícies forem interrompidas por objetos de outro tipo, uma boa composição pode então resultar, desde que suas linhas principais se combinem habilmente.

Variedade é igualmente necessária a essa composição: tanto quanto o contraste. O artista encontra ambos em objetos ásperos; e nenhum dos dois em objetos lisos. Ele pode, é verdade, encontrar certo grau de variedade no contorno de um objeto suave: mas de modo algum em grau suficiente para satisfazer o olho, a não ser que ele inclua também a superfície.

\footnotetext{
${ }^{21}$ A linguagem, como a luz, é um meio; e o verdadeiro estilo filosófico, como a luz de uma janela face norte, revela clara e distintamente os objetos, sem chamar a atenção para si mesma. É verdade que, se seu objetivo é entreter, a linguagem pode ter maior destaque, colorindo-se dos tons da fantasia: mas quando a informação importa mais que o entretenimento, embora se deva evitar uma luz muito intensa, deve-se evitar, cuidadosamente, uma luz colorida. O estilo de alguns escritores se parece com uma forte luz colocada entre o olho e a coisa a servista. Essa luz mostra a si mesma; e esconde o objeto: e há de se convir que a execução de alguns pintores é tão impertinente quanto o estilo de tais escritores. (N. do A.)

${ }^{22}$ Guido Reni, (1575-1642), pintor italiano de tendências classicistas. (N. do T.)
} 
É em objetos ásperos que se busca, também, o claro-escuro, ao qual se predispõem tão bem quanto as belas composições. Uma luz uniforme ou uma sombra uniforme não produzem qualquer efeito desse tipo. São as várias superfícies dos objetos, a refletir a luz ora para este lado, ora para aquele, que oferecem ao pintor suas variadas oportunidades de concentrar e ajustar tanto suas luzes quanto suas sombras. - Do mesmo modo, a riqueza da luz depende das interrupções e dos pequenos recessos que ela encontra na superfície dos corpos - o que o pintor chama de riqueza de uma superfície não é mais que a variedade dessas pequenas partes; das quais a luz, ao incidir, revela todas as pequenas irregularidades e rudezas; e, na linguagem do pintor, a enriquece. A beleza dos destaques se deve, ela também, à rudeza dos objetos. O que o pintor chama de destaque é uma forte incidência de luz sobre uma parte proeminente de uma superfície, enquanto o resto permanece na sombra.

Ao colorir, também, objetos ásperos dão ao pintor outra vantagem. Corpos lisos são normalmente tão uniformes em sua cor quanto em sua superfície. Em objetos reluzentes, ainda que lisos, a cor pode às vezes variar. Em geral, contudo, o oposto acontece; especialmente nos objetos da paisagem. O flanco suave de uma colina é geralmente de uma cor uniforme; ao passo que a rocha entrecortada se mostra, em sua superfície cinzenta, adornada de manchas de musgo a crescer sobre paredes gotejantes; e no solo irregular alternam-se por toda parte uma cor ocre, um cascalho cinzento ou um barro cor de chumbo: de modo que, na verdade, as cores ricas do solo derivam geralmente da sua superfície irregular.

De tal raciocínio, então, inferimos que não é apenas pelas vantagens na execução que os pintores preferem objetos ásperos aos lisos. A própria essência da sua arte o requer.

Já que a beleza pitoresca depende, assim, em grande medida de objetos ásperos, devemos excluir dela toda ideia de lisura? Não enxergamos qualquer imagem bela quando o lago se mostra na tela com seu marmoreum aequor, puro, límpido, liso, como o espelho polido?

Admitimos que ele é pitoresco: mas devemos, ao mesmo tempo, lembrar que, na verdade, a lisura do lago existe mais na realidade que na aparência. Se o pintássemos de um único tom, ele seria certamente um objeto simplório e tedioso. Mas ao olho ele parece entrecortado por tons de vários tipos; pelas ondulações da água; ou pelos reflexos de todos os objetos ásperos à sua volta.

Isso se aplica também a outros corpos lustrosos. Embora o cavalo de um tipo rústico, como já observamos, ou alquebrado pelo esforço, seja mais adequado ao pincel que quando bem-alimentado ou com seu pêlo escovado a reluzir, neste último estado ele pode ainda assim ser pitoresco. Mas o que o torna assim não é seu pêlo liso e brilhoso. O que produz o efeito é a aparente interrupção dessa lisura por uma variedade de sombras e cores. Por toda parte, sob a superfície lustrosa, ficam aparentes a distensão e a 
interação de seus músculos - ele todo é tão lubricus aspici²3, tão continuamente incidem e dançam sobre ele os reflexos luminosos, que o olho esquece a cobertura lisa; e se compraz em deslizar para cima e para baixo em meio a essas transições infinitas, que, em certo grau, suprem de aspereza o conjunto.

Isso se aplica, também, à plumagem dos pássaros. Nada é mais delicado, nada é mais suave ao toque; ainda assim, ela é certamente pitoresca. Mas o efeito não se deve à lisura da superfície - o que admiramos não é ela: é a descontinuidade das cores: é o verde ou o púrpura brilhantes que se transformam, por vezes, num rico azul ou num preto aveludado, tomando ao mesmo tempo um meiotom; e assim por diante, passando por todas as variedades da cor. Ou, se a cor não muda, é a variação harmoniosa dos tons que admiramos nessas elegantes pinceladas da natureza. A uniformidade da superfície não é mais que espaço onde se aplicam as cores. Em si mesma, não é mais admirável que a planura da tela. Mesmo a plumagem do cisne, que ao observador distraído parece ter apenas um tom, apresenta na verdade uma miríade de sombras sutis e pontos brilhantes, perceptíveis num instante ao olho pitoresco.

Do mesmo modo pode um bloco de mármore polido ser pitoresco; mas apenas quando o polimento evidencia os belos veios, que em aparência entrecortam a superfície com uma variedade de linhas e cores. Se o mármore for perfeitamente branco o efeito se desfaz. De modo análogo pode um espelho ter beleza pitoresca; mas esta deriva apenas de seus reflexos. Se nada refletir ele é insípido.

Na estatuária, constatamos às vezes que um artista inferior dá polimento ao seu mármore porque pensa, assim, compensar sua inabilidade com um lustro excelente. $O$ resultado mostra quão pequena é a importância do lustro para o conceito de pitoresco. Quando a luz incide sobre o pelo brilhante um cavalo de raça, ela incide sobre linhas e músculos naturais; e é, por isso, baseada na verdade. Mas o polimento de uma pele de mármore é artificial ${ }^{24}$. Estas luzes são, portanto, falsas. E o lustro, sendo aí quase tudo o que existe para admirar, desagrada. E transforma, por assim dizer, o ruim em pior.

Não queremos afirmar, com tudo isso, que uma simples superfície lisa não pode de modo algum ser pitoresca. Em contraste, ela certamente pode: mais ainda, como contraste ela é frequentemente necessária. A beleza de uma cabeça idosa é grandemente realçada pelo brilho da careca; e as partes mais ásperas de uma rocha devem necessariamente se cercar de outras mais lisas. Seja como for, para tornar um objeto especialmente pitoresco, certa proporção de aspereza é necessária, em quantidade suficiente, pelo menos, para criar uma oposição; a qual, num objeto simplesmente belo, é desnecessária.

\footnotetext{
${ }^{23}$ Literalmente, "escorregadio de se ver" (Horácio, Ode XIX, 8). (N. do T.)

${ }^{24} \mathrm{Em}$ toda pele humana colocada entre o olho e a luz existe um grau de polimento. Não me refiro aqui a um polimento deste tipo, o qual o mármore, em certo grau, sempre possui, bem como a pele humana; mas do polimento mais acabado que se possa dar ao mármore; e que causa sempre um péssimo efeito. Se eu quisesse um exemplo, o busto do arcebispo Boulter na abadia de Westminster serviria à maravilha. (N. do A.)
} 
Um adversário implicante pode argumentar que onde há lisura há sempre aspereza. A planície mais lisa compõe-se de muitas partes ásperas, e a rocha mais agreste de muitas partes lisas; e há tal variedade de graus em ambos os casos, que é difícil estabelecer os limites precisos do liso e do áspero.

A isto, bastaria responder que a tarefa do olho pitoresco é observar a natureza, não analisar a matéria. Ele lança seus olhares de maneira abrangente. Abarca num relance largas porções do espaço. Examina as partes, mas nunca desce até as partículas.

Tendo-se, assim, a partir de uma variedade de exemplos, procurado mostrar que a aspereza, seja real ou aparente, constitui a diferença essencial entre o belo e o pitoresco, poder-se-ia esperar que apontássemos a razão dessa diferença. É bastante óbvio o porquê da preferência do pintor por objetos ásperos sobre objetos lisos ${ }^{25}$ : mas não é tão óbvia a razão pela qual a aspereza faria uma diferença essencial entre os objetos da natureza e os objetos da representação artificial.

A essa questão, poderíamos responder que a arte desagrada ao olho pitoresco, que se deleita apenas na natureza: e que, uma vez que na arte predomina a regularidade, que é apenas outro nome para a lisura, e que nas imagens da natureza predomina a irregularidade, que é apenas outro nome para a aspereza, temos aqui uma solução para nossa pergunta.

Mas essa solução é satisfatória? Temo que não. Embora a regularidade seja frequente na arte, não se segue ela o deva ser em toda a arte. O olho pitoresco, é verdade, encontra seus objetos principais na natureza; mas também se deleita nas imagens artísticas, se elas possuem as características que ele requer. A natureza de um pintor é o que quer que ele imite; seja natural ou artificial a categoria em que se costuma enquadrar o objeto. Há melhor ornamento em paisagens que as ruínas de um castelo? Que pintor as rejeita por serem artificiais? - Que belos efeitos Vandervelt ${ }^{26}$ não obtém de navios? Nas mãos de tal mestre, não fornecem eles formas tão belas quanto praticamente qualquer outra em todo o universo de objetos pitorescos? - E que faria o pintor de temas históricos sem seus drapejados para combinar, contrastar e harmonizar suas figuras? Despidas, não poderiam jamais ser agrupadas. Como poderia ele contar sua história sem armas; utensílios religiosos; e a rica mobília dos banquetes? Muitos destes itens contribuem grandemente para embelezar suas pinturas com formas agradáveis.

Onde, então, buscar nossa resposta sobre o fundamento último da beleza pitoresca? Talvez na união feliz entre a simplicidade e a variedade; para a qual as ideias ásperas contribuem decisivamente. Uma vasta planície é um objeto simples. É somente a continuação de uma ideia uniforme. Mas a mera simplicidade de uma planície não produz beleza. Entrecorte sua superfície, então, como se fez à do jardim;

\footnotetext{
${ }^{25}$ Ver p. 19, por exemplo (N. do A.). Cilpin refere-se aqui à sua discussão da aspereza e da lisura em uma página anterior da edição de 1794 deste ensaio. (N. do T.)

${ }^{26}$ Willem van de Velde (1633-1707), o Jovem, pintor de marinas holandês. (N. do T.)
} 
adicione árvores, rochas e declives; em outras palavras, dê-lhe aspereza, e você lhe dará também variedade. Desse modo, ao enriquecer as partes de um todo coeso com aspereza, você combina numa só as idéias de simplicidade e variedade; e disso resulta o pitoresco. - Será esta uma reposta satisfatória à nossa questão?

De modo algum. Simplicidade e variedade são fontes do belo tanto quando do pitoresco. Por que razão o arquiteto entrecorta a fachada de seu prédio com ornamentos? Não está assim adicionando variedade à simplicidade? O próprio ferreiro reconhece esse princípio quando adiciona círculos ornamentais e espirais em seus atiçadores e tenazes. É assim na natureza; e, ao entrecortá-la, aperfeiçoaremos nossa planície na realidade tanto quanto na tela. - Num jardim ornamentado o critério é outro. Aí todo objeto é elegante e bem-cuidado. O que não o for perturbará a harmonia, e aspereza será desordem.

Devemos, então, buscar outro caminho, e procurar uma resposta à nossa questão na natureza da arte da pintura? Sendo esta uma arte estritamente imitativa, os objetos privilegiados pelo olho pitoresco serão, evidentemente, aqueles que mais facilmente podem ser imitados. Quanto mais marcantes forem seus traços, mais intenso será o efeito da imitação; e, uma vez que os objetos ásperos possuem os traços mais marcantes, eles serão, consequentemente, os mais vantajosos para a representação. Será esta reposta mais satisfatória?

Muito pouco, na verdade. Todo pintor sabe que um objeto liso pode ser imitado tão correta e facilmente quanto um objeto áspero.

Devemos então tomar o caminho oposto, e dizer exatamente o inverso (já que aqueles em dificuldades dirão não importa o quê): que a pintura não é uma arte estritamente imitativa, mas ilusória que através da mistura de cores, e da arte peculiar de aplicá-las, o pintor produz um simulacro de natureza a determinada distância, o qual, visto de perto, mostra-se bastante diferente - que os objetos a que chamamos pitorescos o são na medida em que se adéquam a essa arte - e que, uma vez que ela é mais dissimulada em pinceladas bruscas, objetos desse tipo são, evidentemente, os mais pitorescos. Chegamos agora a uma resolução satisfatória do problema?

Não mais do que antes. Muitos pintores renomados não utilizaram o estilo brusco de pintura; e suas obras são tão admiráveis quanto as daqueles que o preferiram: tampouco, em suas telas, são menos pitorescos os objetos ásperos: em outras palavras, eles pintam suavemente a aspereza.

Assim desenganados, devemos, no autêntico espírito investigativo, persistir? Ou honestamente abandonar a causa, e admitir nossa incapacidade em buscar a fonte dessa diferença? Temo que esta seja a verdade, não importa quão dogmáticos possamos parecer. Investigações de princípios chegam raramente a bom termo. Ainda que chegassem, novas dúvidas surgiriam. Os próprios princípios de nossa 
arte seriam questionados. Dificuldades começariam já vestibulum ante ipsum. ${ }^{27}$ Precisaríamos nos perguntar: o que é a beleza? O que é o gosto? Paremos por um momento, e escutemos os debates dos doutos sobre esses temas. Eles nos mostrarão, pelo menos, que, por mais que desejemos fixar princípios, nossas investigações raras vezes serão satisfatórias.

Um filósofo nos dirá que o gosto é apenas o refinamento de nossas próprias ideias. Todo homem traz em si uma porção natural de gosto, cujas sementes são inatas. Tudo depende de sua cultivação.

Outro filósofo, seguindo a analogia da natureza, observa que, assim como todos temos faces diferentes, podemos certamente supor que o mesmo vale para nossas mentes. Ele rejeita, assim, a ideia de gosto inato; e, no lugar dessa noção, faz da utilidade o critério tanto do gosto quanto da beleza.

A um terceiro filósofo, a ideia de utilidade parece tão absurda quando a de gosto inato ao segundo. Como, exclama ele, não posso admirar a beleza de um resplandecente pôr-do-sol até que eu investigue a utilidade daquela peculiar radiância na atmosfera? Ele deseja então que houvesse entre nós um pouco menos de filosofia e um pouco mais de senso comum. O senso comum é desprezado como outras coisas comuns: mas, em sua opinião, se fizéssemos do senso comum o critério tanto da arte quanto da ciência, estaríamos mais próximos da verdade.

Um quarto filósofo admite que o senso comum seja critério apenas nos assuntos corriqueiros da vida. O butim da natureza nos supriu de vários outros sentidos adequados aos objetos com os quais interagimos: e, no que toca a questões de gosto, ele nos supriu daquele que, assegura o filósofo, todos sentimos dentro de nós, o senso da beleza.

Bah!, diz outro douto investigador, o que é um senso da beleza? Senso é um conceito vago, assim como beleza; e é impossível que qualquer coisa definida possa surgir de termos tão inexatos. Mas se deixarmos de lado o senso da beleza, e adotarmos a proporção, estaremos na trilha certa. A proporção é o grande princípio do gosto e da beleza. Admitimo-la tanto nas linhas quanto nas cores; e, de fato, é de acordo com ela que julgamos todas as ideias referentes à elegância.

Correto, diz um admirador dos antigos; mas essa proporção dever ter uma regra, ou nada ganhamos: e uma regra de proporção certamente existe: mas em vão a buscaremos. O segredo se perdeu. Os antigos o possuíam. Conheciam muito bem os princípios da beleza; e possuíam aquela regra infalível que em todas as coisas Ihes ajustava o gosto. Observamo-la mesmo nos mais simples de seus vasos. Nas obras deles, a proporção, embora varie sob mil formas, permanece a mesma; e, se ao menos pudéssemos

${ }_{27}$ Trecho da Eneida de Virgílio (II, 469): "Diante do próprio vestíbulo" (isto é, da própria entrada): Gilpin quer dizer que as dificuldades começariam já no início da investigação. (N. do T.) 
descobrir seus princípios de proporção, possuiríamos o arcano dessa ciência; e poderíamos resolver nossas disputas sobre o gosto com a maior facilidade.

Assim avançamos em nossas investigações sobre os primeiros princípios, sem final em vista e sem satisfação. O entendimento humano não está à altura dessa busca. Na filosofia os investigamos em vão e assim na física - na metafísica - na moral. Mesmo nas belas-artes, onde o assunto, pode-se supor, é menos recôndito, descobrimos que a investigação é igualmente vaga. Ficamos confusos e perplexos; mas não esclarecidos. Tudo é incerteza, desperdício e jogo de palavras; a velha disputa

Empedocles, an Stertinii deliret acumen?28

Em resumo, se uma causa é suficientemente entendida, ela pode sugerir descobertas úteis. Mas se ela não o for (e que certeza temos nessas investigações?), sem dúvida conduzirá ao erro.

28 "O tolo é Empédocles ou o perspicaz Estertínio?" (Horácio, Epístola XII, 29). (N. do T.) 


\section{On Picturesque Beauty}

Disputes about beauty might perhaps be involved in less confusion, if a distinction were established, which certainly exists, between such objects as are beautiful and such as are picturesque between those, which please the eye in their natural state, and those, which please from some quality, capable of being illustrated by painting.

Ideas of beauty vary with the objects, and with the eye of the spectator. The stone-mason sees beauties in a well-jointed wall, which escape the architect, who surveys the building under a different idea. And thus the painter, who compares his object with the rules of his art, sees it in a different light from the man of general taste, who surveys it only as simply beautiful.

As this difference therefore between the beautiful, and the picturesque appears really to exist, and must depend on some peculiar construction of the object; it may be worth while to examine, what that peculiar construction is. We inquire not into the general sources of beauty, either in nature, or in representation. This would lead into a nice, and scientific discussion, in which it is not our purpose to engage. The question simply is, What is that quality in objects, which particularly marks them as picturesque?

In examining the real object, we shall find, one source of beauty arises from that species of elegance, which we call smoothness, or neatness; for the terms are nearly synonymous. The higher the marble is polished, the brighter the silver is rubbed, and the more the mahogany shines, the more each is considered as an object of beauty: as if the eye delighted in gliding smoothly over a surface.

In the class of larger objects the same idea prevails. In a pile of building we wish to see neatness in every part added to the elegance of the architecture. And if we examine a piece of improved pleasureground, every thing rough, and slovenly offends.

Mr. Burke, enumerating the properties of beauty, considers smoothness as one of the most essential. "A very considerable part of the effect of beauty, says he, is owing to this quality: indeed the most considerable: for take any beautiful object, and give it a broken, and rugged surface, and however well-formed it may be in other respects, it pleases no longer. Whereas, let it want ever so many of the other constituents, if it want not this, it becomes more pleasing, than almost all the others without it." ${ }^{29}$ How far Mr. Burke may be right in making smoothness the most considerable source of beauty, I rather doubt $^{30}$. A considerable one it certainly is.

\footnotetext{
${ }^{29}$ Upon the sublime and beautiful, page 213 .

${ }^{30} \mathrm{Mr}$. Burke is probably not very accurate in what he farther says on the connection between beauty, and diminutives. - Beauty excites love; and a loved object is generally characterized by diminutives. But it does not follow, that all objects characterized by diminutives, tho they may be so because they are loved, are therefore beautiful. We often love them for their moral qualities; their affections; their gentleness; or their docility. Beauty, no doubt, awakens love; but also excites admiration, and respect. This
} 
Thus then, we suppose, the, matter stands with regard to beautiful objects in general. But in picturesque representation it seems somewhat odd, yet perhaps we shall find it equally true, that the reverse of this is the case; and that the ideas of neat and smooth, instead of being picturesque, in reality strip the object, in which they reside, of all pretensions to picturesque beauty. — Nay, farther, we do not scruple to assert, that roughness forms the most essential point of difference between the beautiful, and the picturesque; as it seems to be that particular quality, which makes objects chiefly pleasing in painting. —I use the general term roughness; but properly speaking roughness relates only to the surfaces of bodies: when we speak of their delineation, we use the word ruggedness. Both ideas however equally enter into the picturesque; and both are observable in the smaller, as well as in the larger parts of nature - in the outline, and bark of a tree, as in the rude summit, and craggy sides of a mountain.

Let us then examine our theory by an appeal to experience; and try how far these qualities enter into the idea of picturesque beauty and how far they mark that difference among objects, which is the ground of our inquiry.

A piece of Palladian architecture may be elegant in the last degree. The proportion of it's parts the propriety of it's ornaments - and the symmetry of the whole may be highly pleasing. But if we introduce it in a picture, it immediately becomes a formal object, and ceases to please. Should we wish to give it picturesque beauty, we must use the mallet, instead of the chisel: we must beat down one half of it, deface the other, and throw the mutilated members around in heaps. In short, from a smooth building we must turn it into a rough ruin. No painter, who had the choice of the two objects, would hesitate which to chose.

Again, why does an elegant piece of garden-ground make no figure on canvas? The shape is pleasing; the combination of the objects, harmonious; and the widening of the walk in the very line of beauty. All this is true, but the smoothness of the whole, tho right, and as it should be in nature, offends in picture. Turn the lawn into a piece of broken ground: plant rugged oaks instead of flowering shrubs: break the edges of the walk: give it the rudeness of a road; mark it with wheel-tracks; and scatter around a few stones, and brush wood y in a word, instead of making the whole smooth, make it rough; and you make it also picturesque. All the other ingredients of beauty it already possessed.

You sit for your picture. The master, at your desire, paints your head combed smooth, and powdered from the barber's hand. This may give it a more striking likeness, as it is more the resemblance

combination forms the sentiment, which prevails, when we look at the Apollo of Belvidere, and the Niobe. No man of nice discernment would characterize these statues by diminutives. There is then a beauty, between which and diminutives there is no relation; but which, on the contrary, excludes them: and in the description of figures, possessed of that species of beauty, we seek for terms, which recommend them more to our admiration than our love. 
of the real object. But is it therefore a more pleasing picture? I fear not. Leave Reynolds to himself, and he will make it picturesque: he will throw the hair dishevelled about your shoulders. Virgil would have done the same. It was his usual practice in all his portraits. In his figure of Ascanius, we have the fusos crines; and in his portrait of Venus, which is highly finished in every part, the artist has given her hair,

... diffundere ventis ${ }^{31}{ }^{32}$.

Modern poets also, who have any ideas of natural beauty, do the same. I introduce Milton to represent them all. In his picture of Eve, he tells us, that

... to her slender waste

Her unadorned golden tresses were

Dishevelled, and in wanton ringlets waved.

That lovely face of youth smiling with all it's sweet, dimpling charms, how attractive is it in life! how beautiful in representation! It is one of those objects, that please, as many do, both in nature, and on canvas. But would you see the human face in it's brightest form of picturesque beauty, examine that patriarchal head. What is it, which gives that dignity of character; that force of expression: those lines of wisdom, and experience; that energetic meaning, so far beyond the rosy hue, or even the bewitching smile of youth? What is it, but the forehead furrowed with wrinkles? the prominent cheek-bone, catching the light? the muscles of the cheek strongly marked, and losing themselves in the shaggy beard? and, above all, the austere brow, projecting over the eye — the feature which particularly struck Homer in his idea of Jupiter ${ }^{33}$, and which he had probably seen finely represented in some statue; in a word, what is it, but the rough touches of age?

\footnotetext{
31 "[to the] winds to scatter". (TN) roughness, which he attributes to Charon:

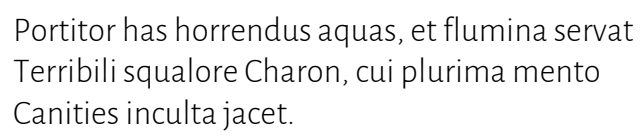

${ }^{32}$ The roughness, which Virgil gives the hair of Venus, and Ascanius, we may suppose to be of a different kind from the squalid

Charon's roughness is, in it's kind, picturesque also; but the roughness here intended, and which can only be introduced in elegant figures, is of that kind, which is merely opposed to hair in nice order. In describing Venus, Virgil probably thought hair, when streaming in the wind, both beautiful, and picturesque, from it's undulating form, and varied tints; and from a kind of life, which it assumes in motion; tho perhaps it's chief recommendation to him, at the moment, was, that it was a feature of the character, which Venus was then assuming.

${ }^{33}$ It is much more probable, that the poet copied forms from the sculptor, who must be supposed to understand them better, from having studied them more; than that the sculptor should copy them from the poet. Artists however have taken advantage of the pre-possession of the world for Homer to secure approbation to their works by acknowledging them to be reflected images 
As an object of the mixed kind, partaking both of the beautiful, and the picturesque, we admire the human figure also. The lines, and surface of a beautiful human form are so infinitely varied; the lights and shades, which it receives, are so exquisitely tender in some parts, and yet so round, and bold in others; it's proportions are so just; and it's limbs so fitted to receive all the beauties of grace, and contrast; that even the face, in which the charms of intelligence, and sensibility reside, is almost lost in the comparison. But altho the human form in a quiescent state, is thus beautiful; yet the more it's smooth surface is ruffled, if I may so speak, the more picturesque it appears. When it is agitated by passion, and it's muscles swoln by strong exertion, the whole frame is shewn to the most advantage. - But when we speak of muscles swoln by exertion, we mean only natural exertions, not an affected display of anatomy, in which the muscles, tho justly placed, may still be overcharged.

It is true, we are better pleased with the usual representations we meet with of the human form in a quiescent state, than in an agitated one: but this is merely owing to our seldom seeing it naturally represented in strong action. Even among the best masters we see little knowledge of anatomy. One will inflate the muscles violently to produce some trifling effect: another will scarce swell them in the production of a laboured one. The eye soon learns to see a defect, tho unable to amend it. But when the anatomy is perfectly just, the human body will always be more picturesque in action, than at rest. The great difficulty indeed of representing strong muscular motion, seems to have struck the ancient masters of sculpture: for it is certainly much harder to model from a figure in strong, momentary action, which must, as it were, be shot flying; than from one, sitting, or standing, which the artist may copy at leisure. Amidst the variety of statues transmitted from their hands, we have only three, or four in very spirited action $^{34}$. Yet when we see an effect of this kind well executed, our admiration is greatly increased. Who does not admire the Laocoon more than the Antinous?

of his conceptions. So Phidias assured his countrymen, that he had taken his Jupiter from the description of that god in the first book of Homer. The fact is, none of the features contained in that image, except the brow, can be rendered by sculpture. But he knew what advantage such ideas, as his art could express, would receive from being connected in the mind of the spectator with those furnished by poetry; and from the just partiality of men for such a poet. He seems therefore to have been as well

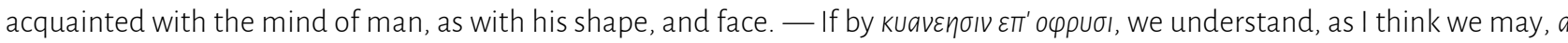
projecting brow, which casts a broad, and deep shadow over the eye. Clarke has rendered it ill by nigris superciliis, which most people would construe into black eye-brows. Nor has Pope, tho he affected a knowledge of painting, translated it more happily by sable eye-brows. - But if Phidias had had nothing to recommend him, except his having availed himself of the only feature in the poet, which was accommodated to his art, we should not have heard of inquirers wondering from whence he had drawn his ideas; nor of the compliment, which it gave him an opportunity of paying to Homer.

${ }^{34}$ Tho there are only perhaps two or three of the first antique statues in very spirited action — the Laocoon, the fighting gladiator, and the boxers - yet there are several others, which are in action — the Apollo Belvidere — Michael Angelo's Torso — Arria and Pætus - the Pietas militaris, sometimes called the Ajax, of which the Pasquin at Rome is a part, and of which there is a repetition more entire, tho still much mutilated, at Florence - the Alexander, and Bucephalus; and perhaps some others, which occur not to my memory. The paucity however of them, even if a longer catalogue could be produced, I think, shews that the ancient sculptors considered the representation of spirited action as an achievement. The moderns have been less daring in attempting 
Animal life, as well as human, is, in general, beautiful both in nature, and on canvas. We admire the horse, as a real object; the elegance of his form; the stateliness of his tread; the spirit of all his motions; and the glossiness of his coat. We admire him also in representation. But as an object of picturesque beauty, we admire more the worn-out cart-horse, the cow, the goat, or the ass; whose harder lines, and rougher coats, exhibit more the graces of the pencil. For the truth of this we may examine Berchem's pictures: we may examine the smart touch of Rosa of Tivoli. The lion with his rough mane; the bristly boar; and the ruffled plumage of the eagle ${ }^{35}$, are all objects of this kind. Smooth-coated animals could not produce so picturesque an effect.

But when the painter thus prefers the cart horse, the cow, or the ass to other objects more beautiful in themselves, he does not certainly recommend his art to those, whose love of beauty makes them anxiously seek, by what means it's fleeting forms may be fixed.

Suggestions of this kind are ungrateful. The art of painting allows you all you wish. You desire to have a beautiful object painted - your horse, for instance, led out of the stable in all his pampered beauty. The art of painting is ready to accommodate you. You have the beautiful form you admired in

it. But I believe connoisseurs universally give the preference to those statues, in which the great masters have so successfully exhibited animated action.

35 The idea of the ruffled plumage of the eagle is taken from the celebrated eagle of Pindar, in his first Pythian ode; which has exercised the pens of several poets; and is equally poetical, and picturesque. He is introduced as an instance of the power of music. In Gray's ode on the progress of poesy we have the following picture of him.

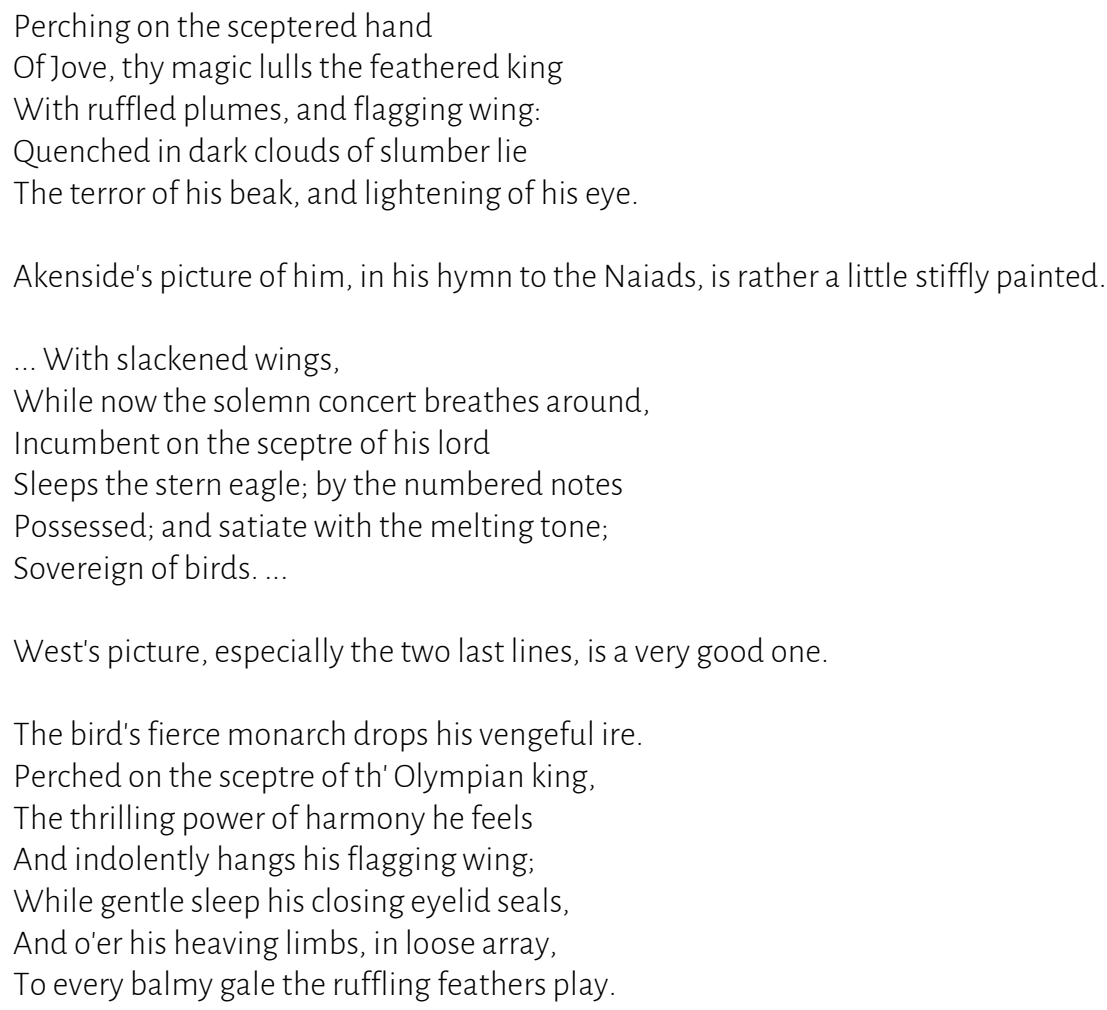


nature exactly transferred to canvas. Be then satisfied. The art of painting has given you what you wanted. It is no injury to the beauty of your Arabian, if the painter think he could have given the graces of his art more forcibly to your cart-horse.

But does it not depreciate his art, if he give up a beautiful form, for one less beautiful, merely because he can give it the graces of his art more forcibly — because it's sharp lines afford him a greater facility of execution? Is the smart touch of a pencil the grand desideratum of painting? Does he discover nothing in picturesque objects, but qualities, which admit of being rendered with spirit?

I should not vindicate him, if he did. At the same time, a free execution is so very fascinating a part of painting, that we need not wonder, if the artist lay a great stress upon it. - It is not however entirely owing, as some imagine, to the difficulty of mastering an elegant line, that he prefers a rough one. In part indeed this may be the case; for if an elegant line be not delicately hit off, it is the most insipid of all lines: whereas in the description of a rough object, an error in delineation is not easily' seen. However this is not the whole of the matter. A free, bold touch is in itself pleasing ${ }^{36}$. In elegant figures indeed there must be a delicate outline - at least a line true to nature: yet the surfaces even of such figures may be touched with freedom; and in the appendages of the composition there must be a mixture of rougher objects, or there will be a want of contrast. In landscape universally the rougher objects are admired; which give the freest scope to execution. If the pencil be timid, or hesitating, little beauty results. The execution then only is pleasing, when the hand firm, and yet decisive, freely touches the characteristic parts of each object.

If indeed, either in literary, or in picturesque composition you endeavour to draw the reader, or the spectator from the subject to the mode of executing it, your affectation ${ }^{37}$ disgusts. At the same time, if some care, and pains be not bestowed on the execution, your slovenliness disgusts as much. Tho perhaps the artist has more to say, than the man of letters, for paying attention to his execution. A truth is a truth, whether delivered in the language of a philosopher, or a peasant: and the intellect receives it as such. But the artist, who deals in lines, surfaces, and colours, which are an immediate address to the eye, conceives the very truth itself concerned in his mode of representing it. Guido's angel, and the angel on a sign-post,

\footnotetext{
${ }^{36}$ A stroke may be called free when there is no appearance of constraint. It is bold, when a part is given for the whole, which it cannot fail of suggesting. This is the laconism of genius. But sometimes it may be free, and yet suggest only how easily a line, which means nothing, may be executed. Such a stroke is not bold, but impudent.

${ }^{37}$ Language, like light, is a medium; and the true philosophic stile, like light from a north-window, exhibits objects clearly, and distinctly, without soliciting attention to itself. In painting subjects of amusement indeed, language may gild somewhat more, and colour with the dies of fancy: but where information is of more importance, than entertainment, tho you cannot throw too strong a light, you mould carefully avoid a coloured one. The stile of some writers resembles a bright light placed between the eye, and the thing to be looked at. The light shews itself; and hides the object: and, it must be allowed, the execution of some painters is as impertinent, as the stile of such writers.
} 
are very different beings; but the whole of the difference consists in an artful application of lines, surfaces, and colours.

It is not however merely for the fake of his execution, that the artist values a rough object. He finds it in many other respects accommodated to his art. In the first place, his composition requires it. If the history painter threw all his draperies smooth over his figures; his groups, and combinations would be very awkward. And in landscape-painting smooth objects would produce no composition at all. In a mountain-scene what composition could arise from the corner of a smooth knoll coming forward on one side, intersected by a smooth knoll on the other; with a smooth plain perhaps in the middle, and a smooth mountain in the distance? The very idea is disgusting. Picturesque composition consists in uniting in one whole a variety of parts; and these parts can only be obtained from rough objects. If the smooth mountains, and plains were broken by different objects, the composition might be good, on a supposition the great lines of it were so before.

Variety too is equally necessary in his composition: so is contrast. Both these he finds in rough objects; and neither of them in smooth. Variety indeed, in some degree, he may find in the outline of a smooth object: but by no means enough to satisfy the eye, without including the surface also.

From rough objects also he seeks the effect of light and shade, which they are as well disposed to produce, as they are the beauty of composition. One uniform light, or one uniform shade produces no effect. It is the various surfaces of objects, sometimes turning to the light in one way, and sometimes in another, that give the painter his choice of opportunities in massing, and graduating both his lights, and shades. - The richness also of the light depends on the breaks, and little recesses, which it finds on the surfaces of bodies. What the painter calls richness on a surface, is only a variety of little parts; on which the light shining shews all it's small inequalities, and roughnesses; or in the painter's language, inriches it. The beauty also of catching lights arises from the roughness of objects. What the painter calls a catching light is a strong touch of light on some prominent part of a surface, while the rest is in shadow. A smooth surface hath no such prominences.

In colouring also, rough objects give the painter another advantage. Smooth bodies are commonly as uniform in their colour, as they are in their surface. In glossy objects, tho smooth, the colouring may sometimes vary. In general however it is otherwise; in the objects of landscape, particularly. The smooth side of a hill is generally of one uniform colour; while the fractured rock presents it's grey surface, adorned with patches of greensward running down it's guttered sides; and the broken ground is every where varied with an okery tint, a grey gravel, or a leaden-coloured clay: so that in fact the rich colours of the ground arise generally from it's broken surface. 
From such reasoning then we infer, that it is not merely for the sake of his execution, that the painter prefers rough objects to smooth. The very essence of his art requires it.

As picturesque beauty therefore so greatly depends on rough objects, are we to exclude every idea of smoothness from mixing with it? Are we struck with no pleasing image, when the lake is spread upon the canvas; the marmoreum æquor, pure, limpid, smooth, as the polished mirror?

We acknowledge it to be picturesque: but we must at the same time recollect, that, in fact, the smoothness of the lake is more in reality, than in appearance. Were it spread upon the canvas in one simple hue, it would certainly be a dull, fatiguing object. But to the eye it appears broken by shades of various kinds; by the undulations of the water; or by reflections from all the rough objects in it's neighbourhood.

It is thus too in other glossy bodies. Tho the horse, in a rough state as we have just observed, or worn down with labour, is more adapted to the pencil, than when his sides shine with brushing, and highfeeding; yet in this latter state also he is certainly a picturesque object. But it is not his smooth, and shining coat, that makes him so. It is the apparent interruption of that smoothness by a variety of shades, and colours, which produces the effect. Such a play of muscles appears, every where, through the fineness of his skin, gently swelling, and sinking into each other - he is all over so lubricus aspici, the reflections of light are so continually shifting upon him, and playing into each other, that the eye never considers the smoothness of the surface but is amused with gliding up, and down, among those endless transitions, which in some degree, supply the room of roughness.

It is thus too in the plumage of birds. Nothing can be softer, nothing smoother to the touch; and yet it is certainly picturesque. But it is not the smoothness of the surface, which produces the effect - it is not this we admire: it is the breaking of the colours: it is the bright green, or purple, changing perhaps into a rich azure, or velvet black; from thence taking a semi-tint; and so on through all the varieties of colour. Or if the colours be not changeable, it is the harmony of them, which we admire in these elegant little touches of nature's pencil. The smoothness of the surface is only the ground of the colours. In itself we admire it no more, than we do the smoothness of the canvas, which receives the colours of the picture. Even the plumage of the swan, which to the inaccurate observer appears only of one simple hue, is in fact varied with a thousand soft shadows, and brilliant touches, at once discoverable to the picturesque eye.

Thus too a piece of polished marble may be picturesque: but it is only, when the polish brings out beautiful veins, which in appearance break the surface by a variety of lines, and colours. Let the marble be perfectly white, and the effect vanishes. Thus also a mirror may have picturesque beauty; but it is only from it's reflections. In an unreflecting state, it is insipid. 
In statuary we sometimes see an inferior artist give his marble a gloss, thinking to atone for his bad workmanship by his excellent polish. The effect shews in how small a degree smoothness enters into the idea of the picturesque. When the light plays on the shining coat of a pampered horse, it plays among the lines, and muscles of nature; and is therefore founded in truth. But the polish of marble-flesh is unnatural ${ }^{38}$. The lights therefore are false; and smoothness being here one of the chief qualities to admire, we are disgusted; and say, it makes bad, worse.

After all, we mean not to assert, that even a simple smooth surface is in no situation picturesque. In contrast it certainly may be: nay in contrast it is often necessary. The beauty of an old head is greatly improved by the smoothness of the bald pate; and the rougher parts of the rock must necessarily be set off with the smoother. But the point lies here: to make an object in a peculiar manner picturesque, there must be a proportion of roughness; so much at least, as to make an opposition; which in an object simply beautiful, is unnecessary.

Some quibbling opponent may throw out, that wherever there is smoothness, there must also be roughness. The smoothest plain consists of many rougher parts; and the roughest rock of many smoother; and there is such a variety of degrees in both, that it is hard to say, where you have the precise ideas of rough and smooth.

To this it is enough, that the province of the picturesque eye is to survey nature; not to anatomize matter. It throws it's glances around in the broad-cast stile. It comprehends an extensive tract at each sweep. It examines parts, but never descends to particles.

Having thus from a variety of examples endeavoured to shew, that roughness either real, or apparent, forms an essential difference between the beautiful, and the picturesque; it may be expected, that we should point out the reason of this difference. It is obvious enough, why the painter prefers rough objects to smooth: but it is not so obvious, why the quality of roughness should make an essential difference between objects of beauty, and objects suited to artificial representation.

To this question, we might answer, that the picturesque eye abhors art; and delights solely in nature: and that as art abounds with regularity, which is only another name for smoothness; and the images of nature with irregularity, which is only another name for roughness, we have here a solution of our question.

\footnotetext{
${ }^{38}$ On all human flesh held between the eye and the light, there is a degree of polish. I speak not here of such a polish as this, which wrought marble always, in a degree, possesses, as well as human flesh; but of the highest polish, which can be given to marble; and which has always a very bad effect. If I wanted an example, the bust of arch-bishop Boulter in Westminster-abbey would afford a very glaring one.
} 
But is this solution satisfactory? I fear not. Tho art often abounds with regularity, it does not follow, that all art must necessarily do so. The picturesque eye, it is true, finds it's chief object in nature; but it delights also in the images of art, if they are marked with the characteristics, which it requires. A painter's nature is whatever he imitates; whether the object be what is commonly called natural, or artificial. Is there a greater ornament of landscape, than the ruins of a castle? What painter rejects it, because it is artificial? - What beautiful effects does Vandervelt produce from shipping? In the hands of such a master it furnishes almost as beautiful forms, as any in the whole circle of picturesque objects? - And what could the history-painter do, without his draperies to combine, contrast, and harmonize his figures? Uncloathed, they could never be grouped. How could he tell his story, without arms; religious utensils; and the rich furniture of banquets? Many of these contribute greatly to embellish his pictures with pleasing shapes.

Shall we then seek the solution of our question in the great foundation of picturesque beauty? in the happy union of simplicity and variety; to which the rough ideas essentially contribute. An extended plain is a simple object. It is the continuation of only one uniform idea. But the mere simplicity of a plain produces no beauty. Break the surface of it, as you did your pleasure-ground; add trees, rocks, and declivities; that is, give it roughness, and you give it also variety. Thus by inriching the parts of a united whole with roughness, you obtain the combined idea of simplicity, and variety; from whence results the picturesque. - Is this a satisfactory answer to our question?

By no means. Simplicity and variety are sources of the beautiful, as well as of the picturesque. Why does the architect break the front of his pile with ornaments? Is it not to add variety to simplicity? Even the very black-smith acknowledges this principle by forming ringlets, and bulbous circles on his tongs, and pokers. In nature it is the same; and your plain will just as much be improved in reality by breaking it, as upon canvas. - In a garden-scene the idea is different. There every object is of the neat, and elegant kind. What is otherwise, is in harmonious; and roughness would be disorder.

Shall we then change our ground; and seek an answer to our question in the nature of the art of painting? As it is an art strictly imitative, those objects will of course appear most advantageously to the picturesque eye, which are the most easily imitated. The stronger the features are, the stronger will be the effect of imitation; and as rough objects have the strongest features, they will consequently, when represented, appear to most advantage. - Is this answer more satisfactory?

Very little, in truth. Every painter, knows that a smooth object may be as easily, and as well imitated, as a rough one. 
Shall we then take an opposite ground, and say just the reverse (as men pressed with difficulties will say any thing) that painting is not an art strictly imitative, but rather deceptive - that by an assemblage of colours, and a peculiar art in spreading them, the painter gives a semblance of nature at a proper distance; which at hand, is quite another thing - that those objects, which we call picturesque, are only such as are more adapted to this art — and that as this art is most concealed in rough touches, rough objects are of course the most picturesque. - Have we now attained a satisfactory account of the matter?

Just as much so, as before. Many painters of note did not use the rough stile of painting; and yet their pictures are as admirable, as the pictures of those, who did: nor are rough objects less picturesque on their canvas, than on the canvas of others: that is, they paint rough objects smoothly.

Thus foiled, should we in the true spirit of inquiry, persist; or honestly give up the cause, and own we cannot search out the source of this difference? I am afraid this is the truth, whatever airs of dogmatizing we may assume. Inquiries into principles rarely end in satisfaction. Could we even gain satisfaction in our present question, new doubts would arise. The very first principles of our art would be questioned. Difficulties would start up vestibulum ante ipsum. We should be asked, What is beauty? What is taste? Let us step aside a moment, and listen to the debates of the learned on these heads. They will at least shew us, that however we may wish to fix principles, our inquiries are seldom satisfactory.

One philosopher will tell us, that taste is only the improvement of our own ideas. Every man has naturally his proportion of taste. The seeds of it are innate. All depends on cultivation.

Another philosopher following the analogy of nature, observes, that as all men's faces are different, we may well suppose their minds to be so likewise. He rejects the idea therefore of innate taste; and in the room of this makes utility the standard both of taste, and beauty.

Another philosopher thinks the idea of utility as absurd, as the last did that of innate taste. What, cries he, can I not admire the beauty of a resplendent sun-set, till I have investigated the utility of that peculiar radiance in the atmosphere? He then wishes we had a little less philosophy among us, and a little more common sense. Common sense is despised like other common things: but, in his opinion, if we made common sense the criterion in matters of art, as well as science, we should be nearer the truth.

A fourth philosopher apprehends common sense to be our standard only in the ordinary affairs of life. The bounty of nature has furnished us with various other senses suited to the objects, among which we converse: and with regard to matters of taste, it has supplied us with what, he doubts not, we all feel within our selves, a sense of beauty.

Pooh! says another learned inquirer, what is a sense of beauty? Sense is a vague idea, and so is beauty; and it is impossible that any thing determined can result from terms so inaccurate. But if we lay 
aside a sense of beauty, and adopt proportion, we shall all be right. Proportion is the great principle of taste, and beauty. We admit it both in lines, and colours; and indeed refer all our ideas of the elegant kind to it's standard.

True, says an admirer of the antique; but this proportion must have a rule, or we gain nothing: and a rule of proportion there certainly is: but we may inquire after it in vain. The secret is lost. The ancients had it. They well knew the principles of beauty; and had that unerring rule, which in all things adjusted their taste. We see it even in their slightest vases. In their works, proportion, tho varied through a thousand lines, is still the same and if we could only discover their principles of proportion, we should have the arcanum of this science; and might settle all our disputes about taste, with great ease.

Thus, in our inquiries into first principles, we go on, without end, and without satisfaction. The human understanding is unequal to the search. In philosophy we inquire for them in vain — in physics in metaphysics - in morals. Even in the polite arts, where the subject, one should imagine, is less recondite, the inquiry, we find, is equally vague. We are puzzled, and bewildered; but not informed, all is uncertainty; a strife of words; the old contest,

Empedocles, an Stertinii deliret acumen?

In a word, if a cause be sufficiently understood, it may suggest useful discoveries. But if it be not so (and where is our certainty in these disquisitions) it will unquestionably mislead. 